\title{
Tamiz neonatal y fenilcetonuria
}

\author{
Dra. Marcela Vela-Amieva, M. en C. Isabel Ibarra González, Dra. Leticia Belmont-Martínez
}

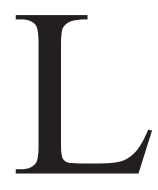

a fenilcetonuria (PKU) es el más paradigmático de los errores innatos del metabolismo. Su descubrimiento por Fölling en 1934 marcó el inicio de las neurociencias al explicar por primera vez el origen bioquímico del retraso mental. ${ }^{1}$ La PKU también es emblemática, pues fue la primera enfermedad genética para la cual se diseñó un tratamiento específico, desarrollado por Woolf y aplicado por Bickel en 1953, quien también demostró que la eficacia del tratamiento era mejor si el paciente lo recibía de manera temprana, en los primeros días de vida. ${ }^{2}$

De igual modo, la PKU fue la enfermedad con la que se originó el tamiz neonatal (TN). Fue la primera afección genética intencionalmente investigada en la población humana. En septiembre de 1963, Robert Guthrie publicó un artículo fundamental en el que mostró como detectar la fenilcetonuria (PKU) en sangre seca depositada en papel filtro, analizada por un método de inhibición bacteriana. ${ }^{3}$ Esta publicación marcó el nacimiento del TN, que es uno de los mayores avances en salud pública.

En este número, Acta Pediátrica de México presenta un panorama sobre los avances y retos del estudio de la PKU en América Latina, así como algunos temas selectos de actualidad sobre el novedoso tratamiento farmacológico para dicha afección. Estos artículos son el resultado del $2^{\circ}$ Foro Latinoamericano de PKU, realizado en la ciudad de

Laboratorio de Errores Innatos del Metabolismo y Tamiz, Instituto Nacional de Pediatría.

www.nietoeditore.com.mx
México en 2011 y representan un esfuerzo multinacional encaminado a compartir experiencias, unificar criterios y mejorar el conocimiento del personal de salud relacionado con la PKU.

No obstante los importantes avances en el diagnóstico y tratamiento de esta enfermedad, en América Latina todavía existen rezagos en la detección y tratamiento temprano de la PKU cuya consecuencia son personas con discapacidad intelectual grave e irreversible, que podría haberse evitado.

Esperamos que este número sea de utilidad para médicos, enfermeras, estudiantes, químicos, residentes y demás personal del sector salud, para que logremos detener la dramática historia natural de esta enfermedad, cerciorándonos de que todos y cada uno de los recién nacidos en nuestro continente sean tamizados y se trate oportuna y adecuadamente a aquellos afectados.

Finalmente, con este número el Instituto Nacional de Pediatría celebra el próximo cincuentenario del inicio del $\mathrm{TN}$ en el mundo. Aun cuando el TN originalmente sirvió sólo para detectar la PKU, en la actualidad se pueden detectar muchas más enfermedades de manera temprana y se visualizan muchas más en el horizonte. El TN llegó para quedarse y su futuro es promisorio.

\section{REFERENCIAS BIBLIOGRÁFICAS}

1. Følling, I. The discovery of phenylketonuria. Acta Paediatrica 1994; 407: 4-10.

2. Bickei H, Gerrard E, Hickmans M. Influence of phenylalanine intake on phenylketonuria. Lancet 1953; 265:812-3.

3. Guthrie R, Susi A. A simple phenylalanine method for detecting phenylketonuria in large populations of newborn infants. Pediatrics. 1963; 32:338-43. 